\title{
Streamer Propagation in a Long Gap in Model Liquids
}

\author{
N.V. Dung, H.K. Høidalen \\ Department of Electric Power \\ Engineering \\ Norwegian University of \\ Science and Technology \\ NO 7491 Trondheim, Norway
}

\author{
D. Linhjell, L.E. Lundgaard \\ Department of Electric Power \\ Engineering \\ SINTEF Energy Research \\ NO 7465 Trondheim, Norway
}

\author{
M. Unge \\ ABB Corporate Research \\ SE 72178 Västerås, Sweden
}

\begin{abstract}
A summary of streamer propagation in Exxsol-D140 and Marcol-52 under various experimental conditions is given. The results are compared to those of cyclohexane and mineral transformer oil. Streamer propagation is polarity and liquid dependent. The breakdown and acceleration voltages are also governed by liquid chemistry. Reduced pressure largely enhances streamer propagation of both polarities. A low ionization potential additive significantly affects positive streamers while an electron scavenger markedly impacts negative streamers. Adding a low ionization potential additive caused positive streamers to behave like those in mineral transformer oil while adding an electron scavenger had the same influence on negative streamers. Processes at the streamer heads are suggested to be responsible for streamer propagation.
\end{abstract}

\section{Introduction}

Mineral transformer oil mainly consists of three components: paraffinic, naphthenic and aromatic/polyaromatic compounds [1]. To understand the mechanisms behind streamer propagation in mineral transformer oil, numerous studies have been performed with hydrocarbon liquids, aromatics, polyaromatics and mineral transformer oil [2-10]. In these studies, various experimental conditions such as additives, hydrostatic pressure, voltage polarity and gap distance were investigated. Aromatic content was found to affect breakdown voltage of both polarities of streamers especially the negative ones [7]. Low ionization potential (IP) additives reduce the breakdown voltage and increase the acceleration voltage, at which the fast streamers appear, of positive streamers [2, 3]. Electron scavengers accelerate and reduce the breakdown voltage of negative streamers [2]. Increased hydrostatic pressure was seen to suppress streamer propagation and raise the breakdown voltage $[8,9,11]$. An increase in viscosity was seen to significantly change streamer shape and reduce time to breakdown [10]. However, the influence of each component on streamer propagation in mineral transformer oil has not been clear, and the systematic investigation of streamer propagation in a mixture of these components has not yet performed.

The purpose of this study is to compare streamer propagation in base liquids (cyclohexane [2], Exxsol oil
$[12,13]$ and Marcol oil [14]) with and without additives with that of mineral transformer oil (Voltesso oil $[5,6]$ ) under similar experimental condition. Cyclohexane consists of only one type of naphthenic molecules, Exxsol oil is constituted by different paraffinic molecules, and Marcol oil is a mixture of paraffinic and naphthenic molecules. $N, N$-dimethylaniline (DMA) and trichloroethylene (TCE) were separately used as additives to investigate the effect of low IP and electron scavenging properties of aromatic compounds on streamer propagation in the base liquids. The concentration of additives was $0.064 \mathrm{M}(\sim 1 \mathrm{wt} \%)$. The influence of reduced pressure and reilluminations on streamer propagation in Marcol oil is recapitulated. Finally, mechanisms for streamer propagation are suggested. The physical and chemical properties of investigated liquids and additives are listed in Table 1. In this study, roughly based on the classification of streamers introduced in $[15,16]$, streamer modes are classified as follows. The $2^{\text {nd }}$ mode streamers propagate with velocity of $1-3 \mathrm{~km} / \mathrm{s}$. The $4^{\text {th }}$ mode streamers are as fast as $100-200 \mathrm{~km} / \mathrm{s}$ for positive polarity and 10 $40 \mathrm{~km} / \mathrm{s}$ for negative polarity.

Table 1 - Physical and chemical properties of investigated liquids and additives.

\begin{tabular}{|c|c|c|c|}
\hline $\begin{array}{ll} & \text { Liquid types } \\
\text { Parameters }\end{array}$ & Exxsol-D140 & Marcol-52 & Voltesso-35 \\
\hline Density at $15^{\circ} \mathrm{C}(\mathrm{g} / \mathrm{cm} 3)$ & 0.825 & 0.828 & 0.88 \\
\hline $\begin{array}{l}\text { Kinematic viscosity at } \\
40^{\circ} \mathrm{C}\left(\mathrm{mm}^{2} / \mathrm{s}\right)\end{array}$ & 4.68 & $7-8$ & 8 \\
\hline Boiling point $\left({ }^{\circ} \mathrm{C}\right)$ & $275-315$ & 316 & $>271$ \\
\hline $\mathrm{IP}(\mathrm{eV})$ & $\sim 10$ & $\sim 10$ & $\sim 10$ \\
\hline Carbon type $(\mathrm{p} / \mathrm{n} / \mathrm{a})^{*}(\%)$ & & $67 / 33 / 0$ & $50 / 40 / 10$ \\
\hline Aromatic content (wt\%) & 0.6 & 0.05 & \\
\hline $\begin{array}{l}\text { Liquid types } \\
\text { Parameters }\end{array}$ & Cyclohexane & DMA & TCE \\
\hline Density at $20^{\circ} \mathrm{C}(\mathrm{g} / \mathrm{cm} 3)$ & 0.77 & 0.96 & 1.46 \\
\hline $\begin{array}{l}\text { Dynamic viscosity at } \\
25^{\circ} \mathrm{C}(\mathrm{mPa} . \mathrm{s})\end{array}$ & 0.89 & 1.53 & 0.54 \\
\hline Boiling point $\left({ }^{\circ} \mathrm{C}\right)$ & 80.7 & 194 & 87.2 \\
\hline IP $(\mathrm{eV})$ & 9.83 & 7.12 & 9.14 \\
\hline
\end{tabular}

*paraffinic/naphthenic/aromatic

\section{Experimental setup}

The experimental setup was described in detail in [2] for cyclohexane, in [12] for Exxsol oil and Marcol oil and in [5] for Voltesso oil. The point-plane gaps were $7.7 \mathrm{~cm}$ for cyclohexane, $8 \mathrm{~cm}$ for Exxsol oil and Marcol 
oil, and 7.5-10 cm for Voltesso oil. The "step" voltages of $0.5 / 1700 \mu$ s were used for all liquids except a voltage waveform of $0.4 / 1400 \mu$ s was used for Voltesso oil.

\section{Results and discussion}

\subsection{Effect of liquid chemistry}

Stopping length is liquid dependent as shown in Fig. 1. DMA had little effect on negative streamers and TCE had little effect on positive streamers, so these combinations are left out of all figures and tables for clarity. Cylohexane is the most favorable liquid for streamer development while Marcol oil shows the biggest resistance to streamer extension. For positive polarity, there is no significant difference in the stopping length between the three liquids until streamers cross more than three fourth of the gap distance. For negative polarity, the influence of liquid chemistry on the stopping length is significant as streamers propagate further than one fifth of the gap distance. It means that the effect of liquid chemistry on the stopping length is more pronounced for negative polarity. In addition, the stopping length also depends on voltage polarity. Positive streamers extend further than negative ones.

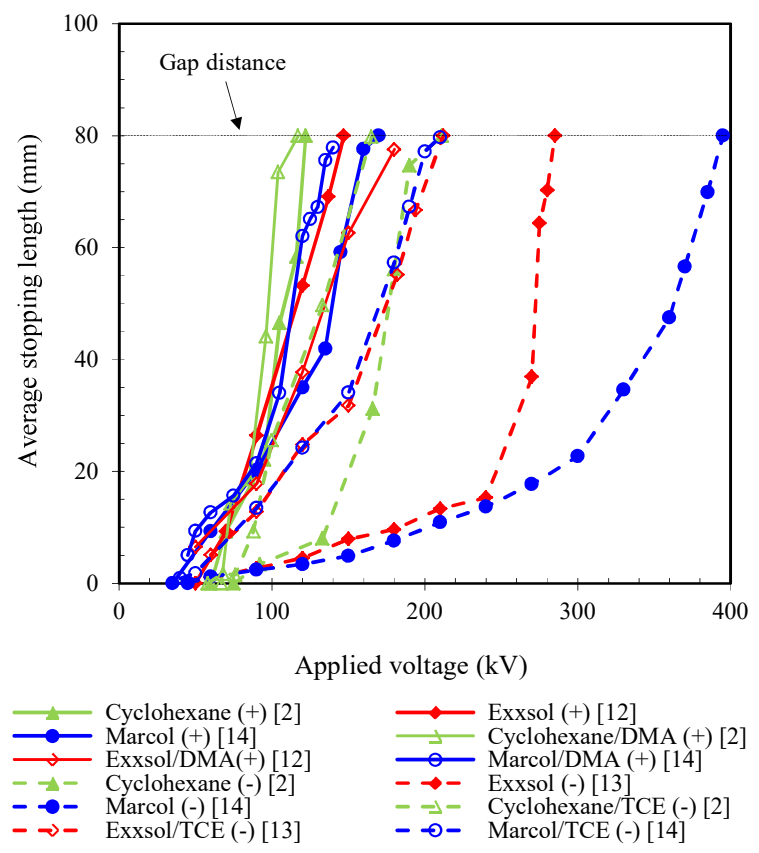

Fig. 1 - Stopping length versus applied voltage.

The influence of liquid chemistry on average velocity is shown in Fig. 2. At a threshold value of applied voltage, known as acceleration voltage $\left(V_{\mathrm{a}}\right)$, the velocity drastically increases and has a tendency to saturate afterwards. For positive streamers, the velocity is slightly affected by liquid chemistry until $V_{\text {a }}$. Above $V_{\text {a }}$, streamers in Marcol oil is about twice as fast as in Exxsol oil. It means that a liquid having a higher $V_{\text {a }}$ correlates to a lower velocity. For negative streamers, the velocity is similar between Marcol oil and Exssol oil except in the applied voltage range of $300-400 \mathrm{kV}$. In this range, Exxsol oil is faster than Marcol oil by a factor of about ten. This is because streamers in Exxsol oil switch from the $1^{\text {st }}$ to $2^{\text {nd }}$ mode to cross the gap distance [13]. This phenomenon was not observed in Marcol. It is seen that positive streamers are about ten times faster than negative ones.

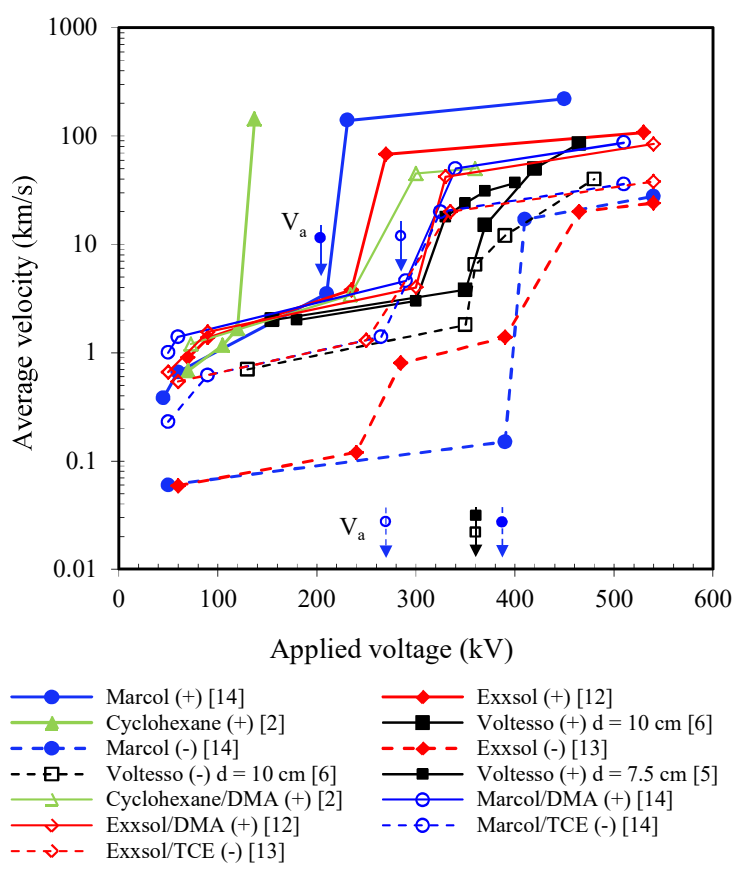

Fig. 2 - Average velocity versus applied voltage.

Table 2 shows the impact of the liquid chemistry on the breakdown voltage $\left(V_{\mathrm{b}}\right)$, which is defined as $50 \%$ breakdown probability, $V_{\mathrm{a}}$ and $V_{\mathrm{a}} / V_{\mathrm{b}}$. It is seen that Marcol oil has the highest value of breakdown voltage while cyclohexane exhibits the lowest breakdown voltage. The reason suggested is that an increase in the stopping length (Fig. 1) will reduce the breakdown voltage. In addition, the breakdown voltage depends more on liquid chemistry for negative streamers. For positive streamers, Voltesso oil reaches the highest values of $V_{\mathrm{a}}$ and $V_{\mathrm{a}} / V_{\mathrm{b}}$ while cyclohexane has the lowest values. It means that Voltesso oil has a good property of suppressing fast streamers. For negative streamers, Exxsol oil and Marcol oil show a better ability of successfully suppressing the fast streamers than Voltesso oil.

\subsection{Effect of additives}

DMA increases stopping length of positive streamers for cyclohexane and Marcol oil while it decreases that of streamers for Exxsol oil as seen in Fig. 1. However, DMA has an insignificant effect on the stopping length of negative streamers $[2,13,14]$. It is seen that TCE drastically increases the stopping length of negative streamers (Fig. 1). In contrast, TCE only slightly affects the stopping length of positive streamers [2, 12, 14].

DMA and TCE strongly affect the average velocity of streamers in model oil (Exxsol oil and Marcol oil) as shown in Fig. 2. DMA increases the velocity of positive 
non-breakdown streamers but decreases that of positive breakdown streamers. It is suggested that the reason is that DMA makes positive streamers more branched (Fig. 3), reducing the maximum electric field of the streamer envelope. TCE increases the velocity of both non-breakdown and breakdown negative streamers. It probably relates to streamer branches becoming thinner (Fig. 3). Clearly, the low IP additive, e.g. DMA, significantly affects positive streamers while the electron scavenger, e.g. TCE, markedly influences negative streamers. Thus, electronic processes are possibly involved in the propagation of streamers.

With the presence of DMA, $V_{\mathrm{a}}$ of model oil is significantly raised to a value of $290-300 \mathrm{kV}$ that is comparable to Voltesso oil (Table 2). DMA also raises the ratio $V_{\mathrm{a}} / V_{\mathrm{b}}$ of model oil to 1.8-2.1, which is similar to the ratio in Voltesso oil (1.9-2.1) (Table 2). Moreover, as seen in Fig. 2, the velocity versus applied voltage with DMA added has a tendency of approaching the velocity in Voltesso oil.

When TCE is added into model oil, the three following effects are observed. First, as shown in Fig. 2, TCE dramatically increases the velocity of negative streamers to a value similar to that in Voltesso oil $(\sim 1 \mathrm{~km} / \mathrm{s})$. Second, both $V_{\mathrm{b}}$ and $V_{\mathrm{a}}$ have a tendency to be reduced to a value comparable to that in Voltesso oil (Table 2). Finally, the velocity of fast mode streamers is increased to that of Voltesso oil (Fig. 2).

It is observed that the ratio $V_{\mathrm{b}(-) \text { (model oil/TCE) }} / V_{\mathrm{b}(+) \text { (model }}$ oil/DMA) is about 1.2-1.5 that is comparable to $V_{\mathrm{b}(-)} / V_{\mathrm{b}(+)}$ of Voltesso oil (1.3). The ratio $V_{\mathrm{a}(-)(\text { model oil/TCE) }} / V_{\mathrm{a}(+)(\text { model }}$ oil/DMA) is approximately $0.82-0.93$ that is in the range of $V_{\mathrm{a}(-)} / V_{\mathrm{a}(+)}$ of Voltesso oil $(\sim 1.0)$.

Consequently, for positive streamers, mixing a small amount of a low ionization potential additive, e.g. DMA, into model oil makes it behave more like mineral transformer oil. For negative streamers, a mixture of TCE and model oil resembles mineral transformer oil very much.

Table 2 $-V_{\mathrm{b}}, V_{\mathrm{a}}$ and $V_{\mathrm{a}} / V_{\mathrm{b}}$ of investigated liquids.

\begin{tabular}{|l|c|c|c|c|c|c|}
\multirow{2}{*}{ Liquid types Polarity } & \multicolumn{3}{|c|}{ Positive } & \multicolumn{3}{c|}{ Negative } \\
\cline { 2 - 8 } & $\begin{array}{c}V_{\mathrm{b}} \\
(\mathrm{kV})\end{array}$ & $\begin{array}{c}V_{\mathrm{a}} \\
(\mathrm{kV})\end{array}$ & $V_{\mathrm{a}} / V_{\mathrm{b}}$ & $\begin{array}{c}V_{\mathrm{b}} \\
(\mathrm{kV})\end{array}$ & $\begin{array}{c}V_{\mathrm{a}} \\
(\mathrm{kV})\end{array}$ & $V_{\mathrm{a}} / V_{\mathrm{b}}$ \\
\hline Cyclohexane [2] & 118 & 125 & 1.0 & 179 & & \\
\hline Cyclohexane/DMA [2] & 102 & 234 & 2.3 & & & \\
\hline Exxsol [12,13] & 145 & 240 & 1.7 & 281 & 390 & 1.4 \\
\hline Exxsol/DMA [12] & 166 & 300 & 1.8 & & & \\
\hline Exxsol/TCE [13] & & & & 205 & 246 & 1.2 \\
\hline Marcol [14] & 162 & 210 & 1.3 & 389 & 390 & 1.0 \\
\hline Marcol/DMA [14] & 137 & 290 & 2.1 & & & \\
\hline Marcol/TCE [14] & & & & 208 & 270 & 1.3 \\
\hline Voltesso d =7.5 cm [5] & 140 & 300 & 2.1 & & & \\
\hline Voltesso d =8 cm [5] & 150 & 320 & 2.1 & 190 & 310 & 1.6 \\
\hline Voltesso d =10cm [6] & 180 & 350 & 1.9 & 230 & 350 & 1.5 \\
\hline
\end{tabular}

\subsection{Effect of reduced pressure}

A vacuum of 3 mbar was maintained above the oil surface during experiments, giving a pressure in the gap of 21-30 mbar due to the oil depth [14]. Reduced pressure significantly increases stopping length as shown in Fig. 4, and reduces the breakdown voltage by about $50 \%$ (Table 3 ). The possible explanation is that a reduction in pressure will either reduce the boiling point of oil or facilitate bubble formation $[17,18]$. This eases the formation of gaseous channels and by this streamer propagation.

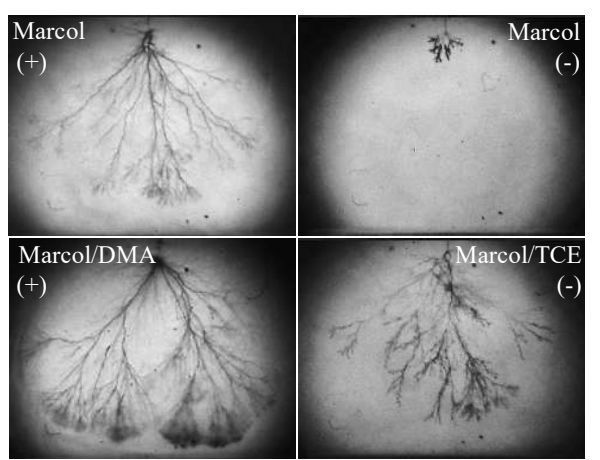

Fig. 3 - Effect of DMA and TCE on streamer shapes at $210 \mathrm{kV}$.

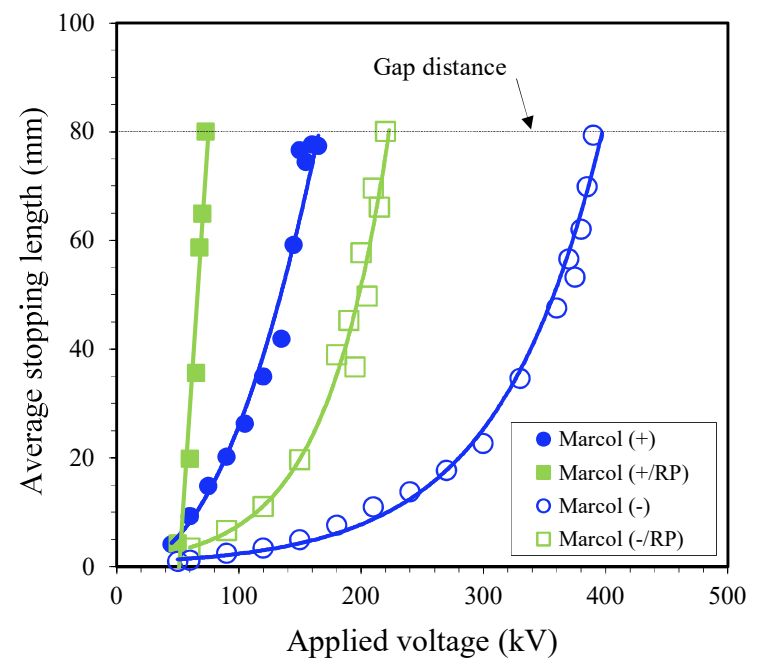

Fig. 4 - Influence of reduced pressure on the stopping length (RP: reduced pressure, data extracted from [14]).

Table 3 - Influence of reduced pressure on $V_{\mathrm{b}}(\mathrm{kV})$.

\begin{tabular}{|c|c|c|}
\hline $\begin{array}{ll}\text { Pressure } & \text { Polarity }\end{array}$ & Positive & Negative \\
\hline Normal ambient pressure & 162.1 & 388.8 \\
\hline Reduced pressure & 70.8 & 215.1 \\
\hline
\end{tabular}

For positive streamers, although reduced pressure makes streamers more branched (Fig. 5), it does not reduce streamer velocity (Fig. 6). This is because an increase in the shielding effect due to more branching is possibly counterbalanced by the enhancement of either oil evaporation or bubble formation processes induced by reduced pressure. In addition, $V_{\mathrm{a}}$ of positive streamers is almost unchanged by reduced pressure. Thus, the appearance of fast streamers possibly depends on only electronic processes at channel tips and there is a threshold value of the electric field at the channel tip for switching from slow to fast streamers. It is seen that inception voltage for $2^{\text {nd }}$ mode streamers and 
acceleration voltage seem unaffected by reduced pressure (Fig. 6). This could indicate that the processes, i.e. avalanches, occur within the liquid phase.

For negative streamers, reduced pressure markedly changes streamer velocity (Fig. 6). It decelerates nonbreakdown streamers but accelerates breakdown ones. This indicates that gaseous processes play an important role in all modes of streamers. In addition, in spite of lower velocity and higher number of branches, the $1^{\text {st }}$ mode streamers can propagate much further under reduced pressure. Thus, the propagation of the $1^{\text {st }}$ mode streamers largely depends on the gaseous processes. Reduced pressure significantly reduces $V_{\mathrm{a}}$ of negative streamers. It means that both electronic and gaseous processes control the occurrence of fast mode negative streamers.

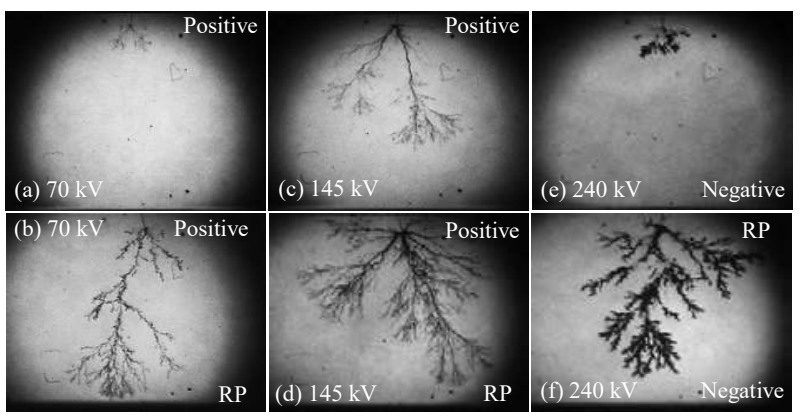

Fig. 5 - Effect of reduced pressure on streamer shapes in Marcol oil (Referred to [14]).

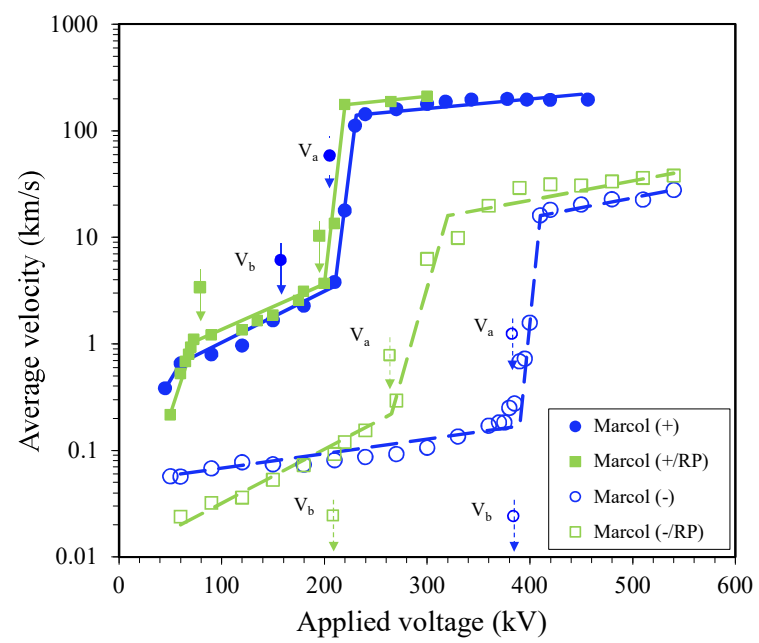

Fig. 6 - Influence of reduced pressure on the average velocity (data extracted from [14]).

\subsection{Effect of reilluminations and streamer modes}

For the $2^{\text {nd }}$ mode streamers, each reillumination occurs during a very short time $(\sim 10 \mathrm{~ns})$ with high luminosity and high current recorded [5]. It means that streamer channels become highly conductive only during reilluminations. Moreover, with reduced pressure, voltage drop along streamer channels is drastically reduced, and the number of reilluminations was seen to decrease [19]. Therefore, reilluminations are suggested to be created by gas discharges inside streamer channels. As reported in [19], reilluminations had insignificant influence on streamer propagation although they largely facilitated the breakdown. In addition, the existence of space charges at the channel tip is proposed in [19]. Consequently, it is suggested that processes taking place at the channel tips are more important than those occurring inside the channels.

The $4^{\text {th }}$ mode positive streamers propagate with very luminous channels and very high velocity of 100$200 \mathrm{~km} / \mathrm{s}$ [12, 14]. Streamer current continuously increases to some amperes [20]. Continuous luminous light is obtained with streak images [12, 14]. Low voltage drop is observed along the streamer channels $(\sim 1 \mathrm{kV} / \mathrm{cm})[21]$.

\section{Suggested mechanisms}

From the above results, a hypothetical model for streamer propagation is suggested as follows. Gaseous plasma is present inside streamer channels while space charges accumulate at the channel tip. Electric field formed by the space charges will govern processes at the channel tip. Due to tip processes, streamer channel will grow as long as the tip field is high enough. When the electric field reaches a critical value, streamers will switch from the $2^{\text {nd }}$ to $4^{\text {th }}$ modes. The possible processes occurring at the channel tips are illustrated in Table 4. Electronic processes in front of streamer heads are possibly impact ionization and field ionization of liquid molecules. For positive streamers, seed electrons for impact ionization of liquid molecules may originate in either partial discharges inside micro-bubbles [22] or photo-ionization of liquid molecules in a stresses volume in front of streamer heads [23]. For negative streamers, the seed electrons are emitted from streamer heads.

Table 4 - Possible processes occurring at the channel tip.

\begin{tabular}{|l|c|c|c|c|}
\hline \multirow{2}{*}{ Tip processes } & \multicolumn{2}{c|}{ Positive streamer } & \multicolumn{2}{c|}{ Negative streamer } \\
\cline { 2 - 5 } & $\begin{array}{c}2^{\text {nd }} \\
\text { mode }\end{array}$ & $\begin{array}{c}4^{\text {th }} \\
\text { mode }\end{array}$ & $\begin{array}{c}2^{\text {nd }} \\
\text { mode }\end{array}$ & $\begin{array}{c}4^{\text {th }} \\
\text { mode }\end{array}$ \\
\hline $\begin{array}{l}\text { Micro bubbles in front } \\
\text { of the channel tips }\end{array}$ & $\times$ & $\times$ & $\times$ & $\times$ \\
\hline $\begin{array}{l}\text { Molecular excitation } \\
\text { and de-excitation }\end{array}$ & $\times$ & $\times$ & $\times$ & $\times$ \\
\hline Photon emission & $\times$ & $\times$ & $\times$ & $\times$ \\
\hline $\begin{array}{l}\text { Electron injection } \\
\text { from streamer heads }\end{array}$ & & & $\times$ & $\times$ \\
\hline Impact ionization & $\times$ & $\times$ & $\times$ & $\times$ \\
\hline Field ionization & & $\times$ & & $\times$ \\
\hline Joule heating & $\times$ & $\times$ & $\times$ & $\times$ \\
\hline $\begin{array}{l}\text { Evaporation of liquid } \\
\text { and bubble formation }\end{array}$ & & & & $\times$ \\
\hline
\end{tabular}

\section{Conclusions}

Streamer propagation in model liquids has been summarized. Streamer propagation depends on liquid chemistry, hydrostatic pressure and voltage polarity. Streamer propagation is a consequence of electronic 
processes in front of streamer heads followed by joule heating and evaporation of liquid. The electronic processes may be dominated by the impact ionization of liquid molecules. However, the field ionization of liquid molecules cannot be ruled out especially for the fastest mode streamers.

\section{Acknowledgements}

This work has been supported by ABB, Norwegian Research Council, and Statnett SF.

\section{References}

[1] T. O. Rouse, "Mineral insulating oil in transformers", IEEE Electr. Insul. Mag., vol. 14, 1998, pp. 6-16.

[2] D. Linhjell, S. Ingebrigtsen, L. E. Lundgaard, and M. Unge, "Streamers in Long Point-Plane Gaps in Cyclohexane with and without Additives under Step Voltage", IEEE 17th Int'l. Conf. Dielectr. Liquids (ICDL), Trondheim (Norway), 2011.

[3] O. Lesaint and M. Jung, "On the relationship between streamer branching and propagation in liquids: influence of pyrene in cyclohexane", $J$. Phys. D: Appl. Phys., vol. 33, 2000, pp. 13601368.

[4] F. M. J. Mccluskey, O. Lesaint, and A. Denat, "Breakdown Processes over Large Distances in Insulating Liquids of Distinct ChemicalCompositions", IEEE Int'l. Sympos. Electr. Insul. (ISEI), Pittsburgh (USA), 1994, pp. 426-429.

[5] O. Lesaint and G. Massala, "Positive streamer propagation in large oil gaps - Experimental characterization of propagation modes", IEEE Trans. Dielectr. Electr. Insul., vol. 5, 1998, pp. 360-370.

[6] G. Massala and O. Lesaint, "A comparison of negative and positive streamers in mineral oil at large gaps", J. Phys. D: Appl. Phys., vol. 34, 2001, pp. 1525-1532.

[7] K. N. Mathes and T. O. Rouse, "Influence of aromatic compounds in oil on pirelli gassing and impulse surge breakdown", Conf. Electr. Insul. and Diel. Phenomena (CEIDP), Washington (USA), 1975, pp. 129-140.

[8] O. Lesaint and P. Gournay, "On the Gaseous Nature of Positive Filamentary Streamers in Hydrocarbon Liquids. 1", J. Phys. D: Appl. Phys., vol. 27, 1994, pp. 2111-2116.

[9] R. Badent, K. Kist, and A. J. Schwab, "The Effect of Hydrostatic-Pressure on Streamer Inception and Propagation in Insulating Oil", IEEE Int'l. Sympos. Electr. Insul. (ISEI), Pittsburgh (USA), 1994, pp. 402-405.

[10] R. Badent, K. Kist, and A. J. Schwab, "The effect of viscosity on streamer propagation in insulating oil under impulse conditions", IEEE 12th Int'l. Conf. Dielectr. Liquids (ICDL), Rome (Italy), 1996, pp. 181-184.
[11] A. Beroual, "Electronic and Gaseous Processes in the Prebreakdown Phenomena of Dielectric Liquids", J. Appl. Phys., vol. 73, 1993, pp. 45284533.

[12] N. V. Dung, H. K. Høidalen, D. Linhjell, L. E. Lundgaard, and M. Unge, "Influence of Impurities and Additives on Positive Streamers in Paraffinic Model Oil", IEEE Trans. Dielectr. Electr. Insul., vol. 19, 2012, pp. 1593-1603.

[13] N. V. Dung, H. K. Hoidalen, D. Linhjell, L. E. Lundgaard, and M. Unge, "Influence of Impurities and Additives on Negative Streamers in Paraffinic Model Oil", IEEE Trans. Dielectr. Electr. Insul., 2013. Accepted for publication.

[14] N. V. Dung, H. K. Høidalen, D. Linhjell, L. E. Lundgaard, and M. Unge, "Effects of reduced pressure and additives on streamers in white oil in long point-plane gap", submitted to J. Phys. D: Appl. Phys., 2013.

[15] O. Lesaint, "Propagation of positive discharges in long liquid gaps", IEEE 12th Int'l. Conf. Dielectr. Liquids (ICDL), Rome (Italy), 1996, pp. 161-166.

[16] R. E. Hebner, The Liquid state and its Electrical Properties. Vol. B193. NATO ASI series, New york plenum press, 1988.

[17] P. Gournay and O. Lesaint, "On the Gaseous Nature of Positive Filamentary Streamers in Hydrocarbon Liquids. 2", J. Phys. D: Appl. Phys., vol. 27, 1994, pp. 2117-2127.

[18] M. Butcher, A. A. Neuber, M. D. Cevallos, J. C. Dickens, and H. Krompholz, "Conduction and breakdown mechanisms in transformer oil", IEEE Trans. Plas. Sci., vol. 34, 2006, pp. 467-475.

[19] N. V. Dung, H. K. Hoidalen, D. Linhjell, L. E. Lundgaard, and M. Unge, "A Study on Positive Streamer Channels in Marcol Oil”, IEEE Int'l. Conf. Electr. Insul. Dielectr. Phenomena, Montreal (Canada), 2012, pp. 365-370.

[20] C. T. Duy, O. Lesaint, A. Denat, and N. Bonifaci, "Streamer Propagation and Breakdown in Natural Ester at High Voltage", IEEE Trans. Dielectr. Electr. Insul., vol. 16, 2009, pp. 1582-1594.

[21] G. Massala and O. Lesaint, "Positive streamer propagation in large oil gaps - Electrical properties of streamers", IEEE Trans. Dielectr. Electr. Insul., vol. 5, 1998, pp. 371-381.

[22] R. P. Joshi, J. F. Kolb, S. Xiao, and K. H. Schoenbach, "Aspects of Plasma in Water: Streamer Physics and Applications", Plasma Processes and Polymers, vol. 6, 2009, pp. 763777.

[23] L. E. Lundgaard, D. Linhjell, and G. Berg, "Streamer/leaders from a metallic particle between parallel plane electrodes in transformer oil", IEEE Trans. Dielectr. Electr. Insul.,vol. 8, 2001, pp. 1054-1063. 